Supporting Information

\title{
Structural and Catalytic Effects of Iron- and Scandium-Doping on a Strontium Cobalt Oxide Electrocatalyst for Water Oxidation
}

\author{
Bryan R. Wygant ${ }^{\mathrm{a}}$, Karalee A. Jarvis ${ }^{\mathrm{b}}$, William D. Chemelewski ${ }^{\mathrm{b}}$, Oluwaniyi Mabayoje ${ }^{\mathrm{a}}$, \\ Hugo Celio ${ }^{\mathrm{b}}$, and C. Buddie Mullins ${ }^{\mathrm{a}, \mathrm{b}, \mathrm{c},{ }^{*}}$ \\ ${ }^{a}$ Department of Chemistry, University of Texas at Austin, Austin, Texas 78712, United States \\ ${ }^{\mathrm{b}}$ Texas Materials Institute, University of Texas at Austin, Austin, Texas 78712, United States \\ ${ }^{\mathrm{c}}$ McKetta Department of Chemical Engineering, University of Texas at Austin, Austin, Texas 78712 , United \\ States \\ *For correspondence: mullins@che.utexas.edu
}

\section{Contents}

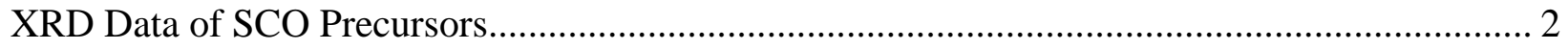

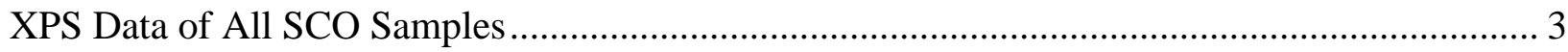

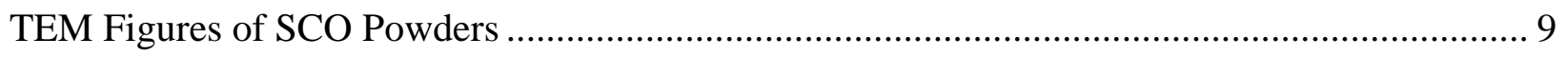

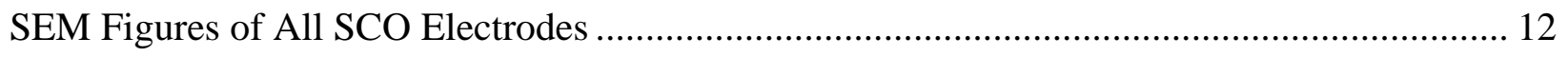

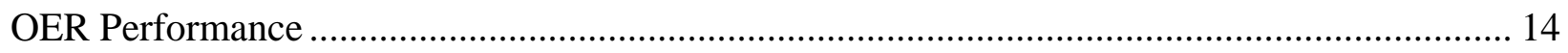

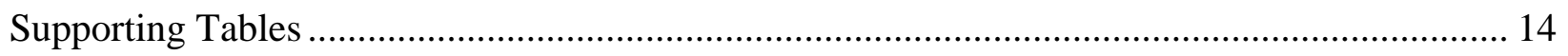




\section{XRD Data of SCO Precursors}
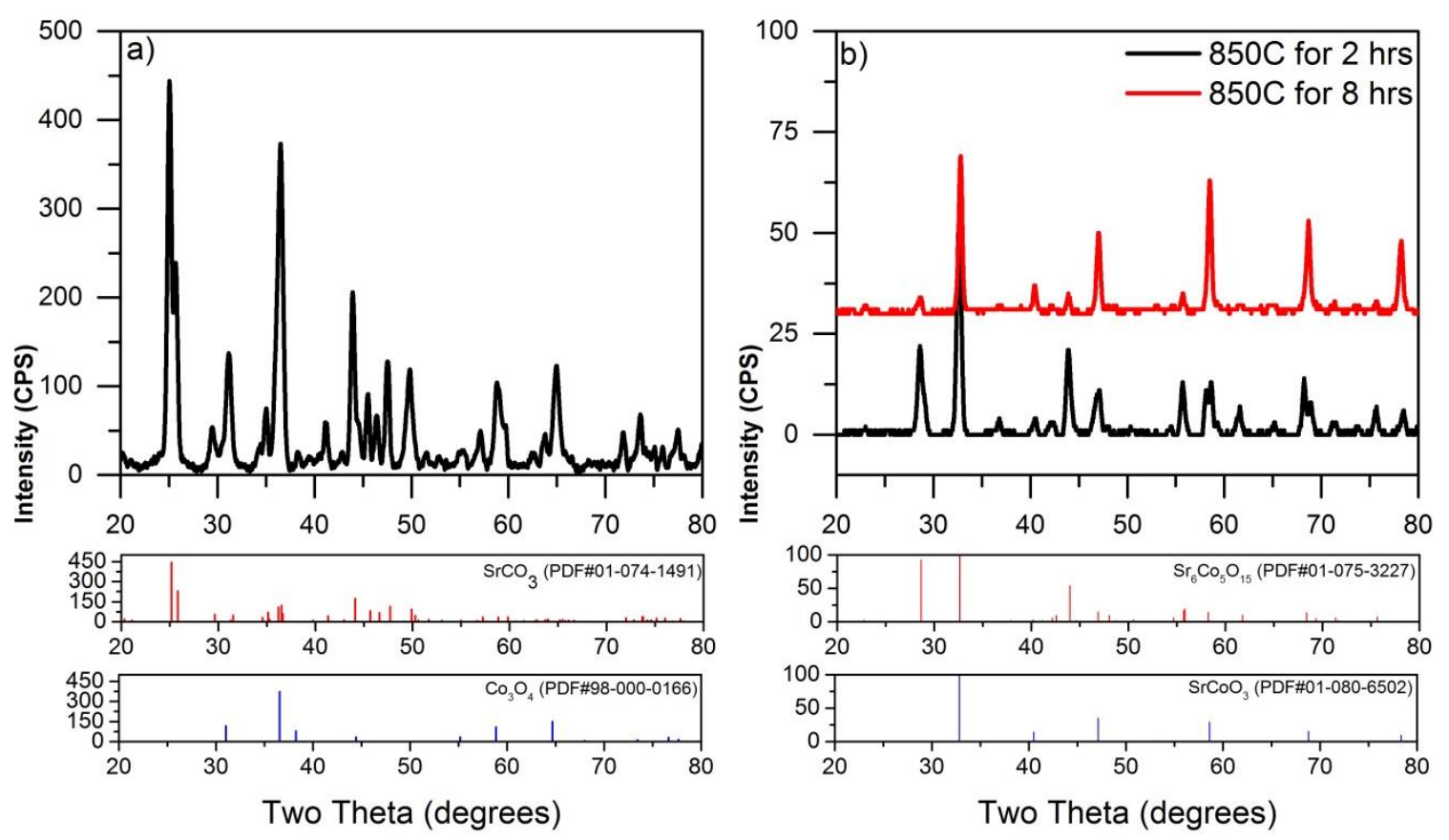

Figure S1. XRD spectra of a) SCO precursor annealed for 4.5 hours at $450^{\circ} \mathrm{C}$, b) SCO precursor annealed at $850^{\circ} \mathrm{C}$ for 2 and 8 hours 


\section{XPS Data of All SCO Samples}
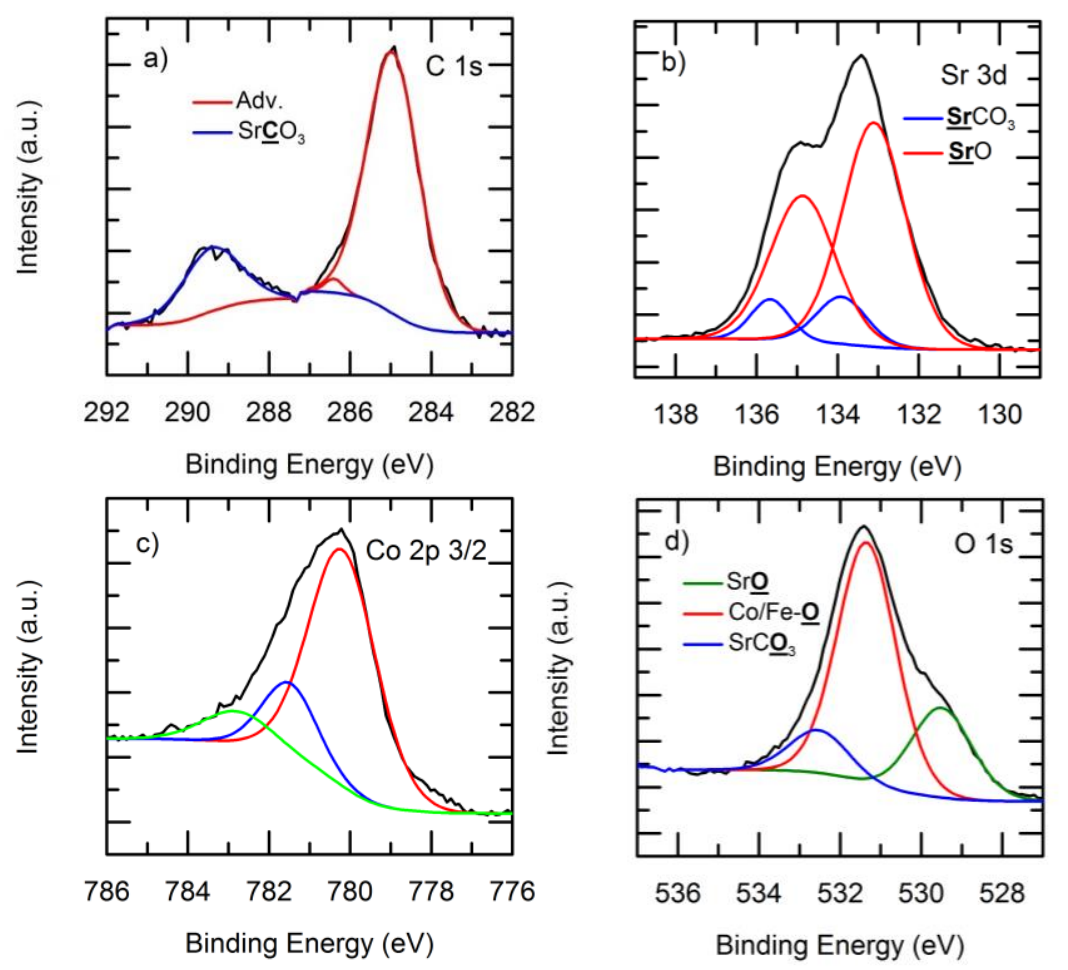

Figure S2. XPS spectra and fitted peaks for the $1 \% \mathrm{Fe}-\mathrm{SCO}$ sample. a) Spectra of the carbon 1s peak. b) Spectra of the strontium 3d 5/2 and 3/2 peaks. c) Spectra of the cobalt 2p peak. d) Spectra of the oxygen 1s peak. 

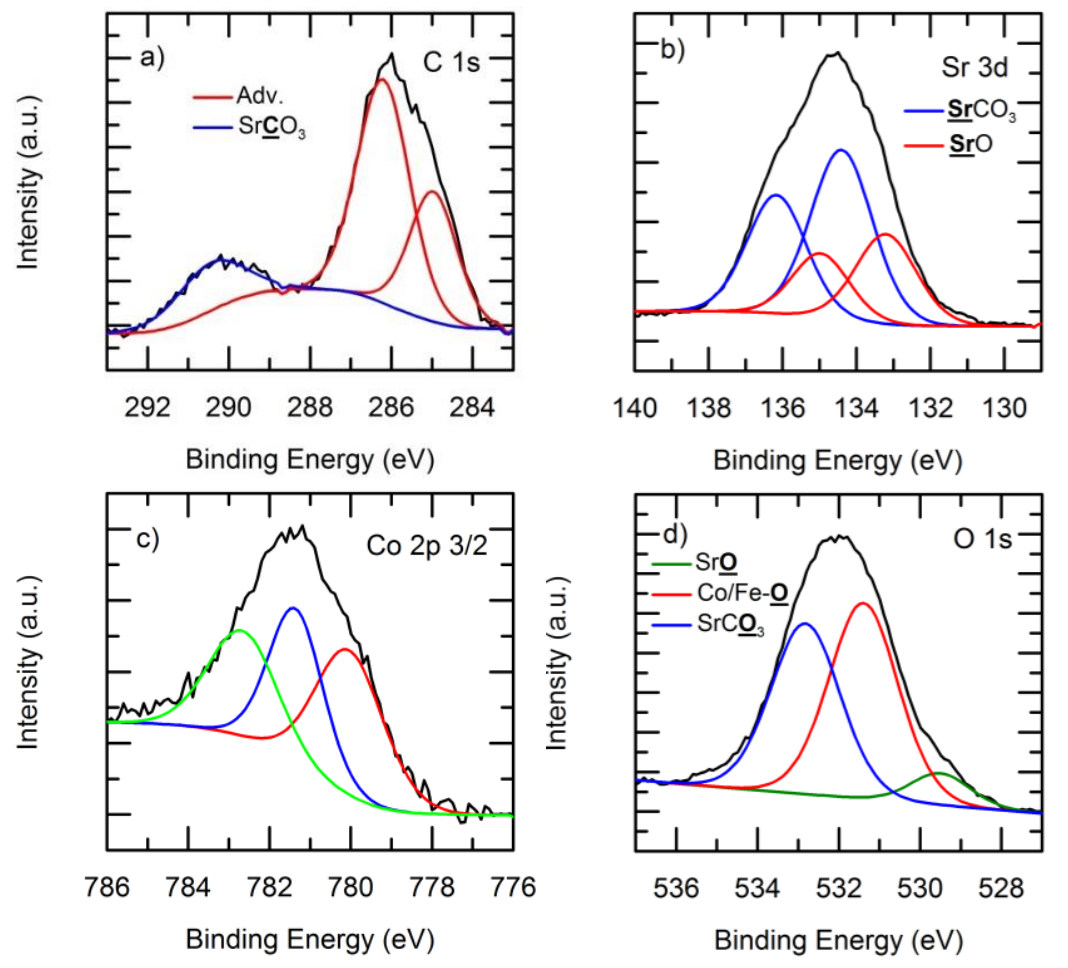

Figure S3. XPS spectra and fitted peaks for the $5 \% \mathrm{Fe}-\mathrm{SCO}$ sample. a) Spectra of the carbon $1 \mathrm{~s}$ peak. b) Spectra of the strontium 3d 5/2 and 3/2 peaks. c) Spectra of the cobalt 2p peak. d) Spectra of the oxygen 1s peak.
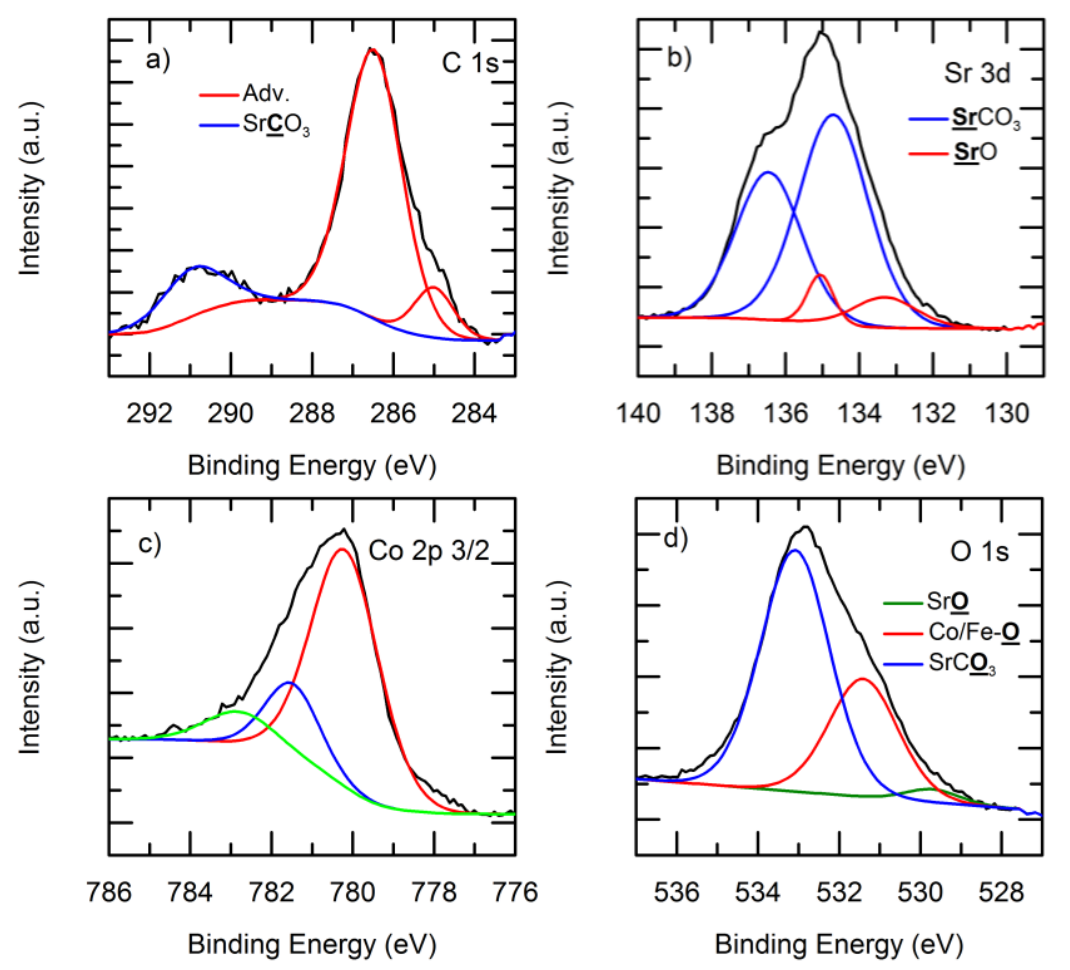

Figure S4. XPS spectra and fitted peaks for the $1 \%$ Sc-SCO sample. a) Spectra of the carbon 1s peak. b) Spectra of the strontium 3d 5/2 and 3/2 peaks. c) Spectra of the cobalt $2 p$ peak. d) Spectra of the oxygen 1s peak. 

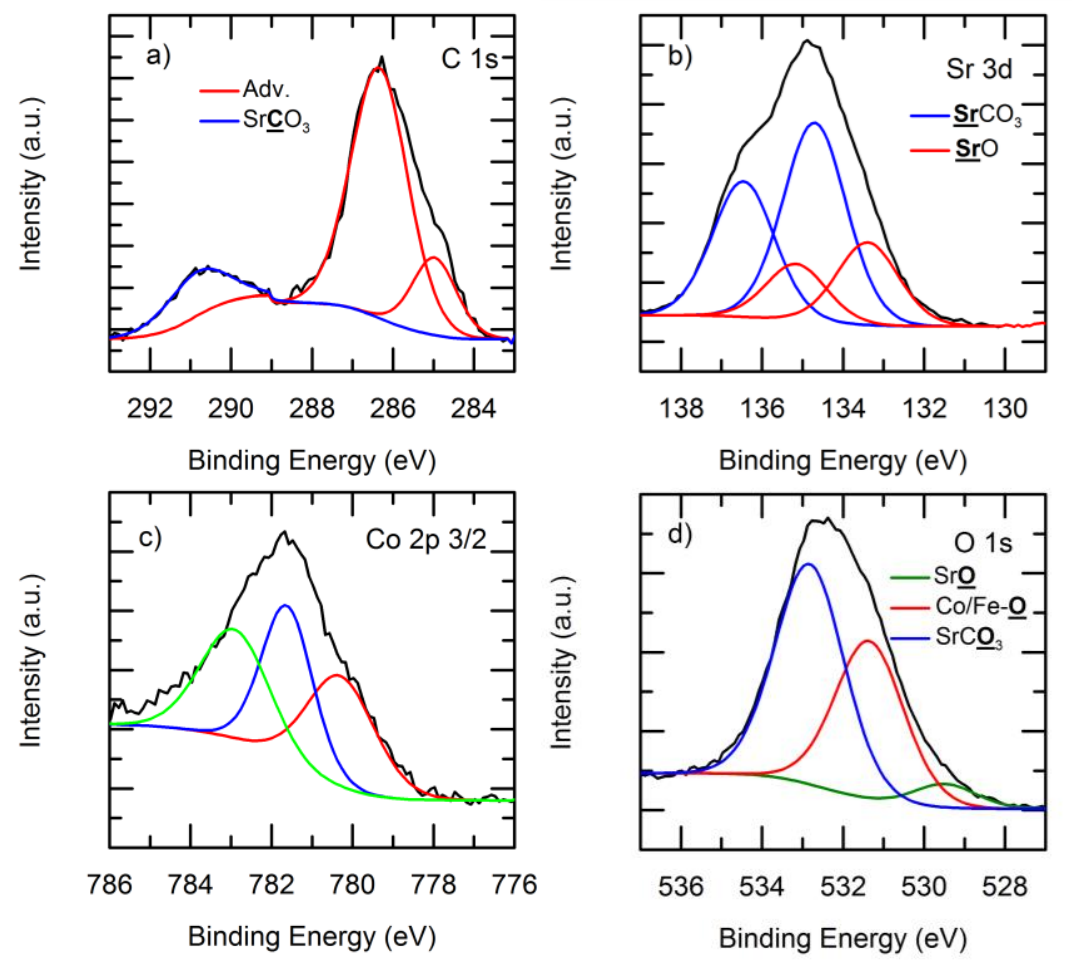

Figure S5. XPS spectra and fitted peaks for the $5 \%$ Sc-SCO sample. a) Spectra of the carbon 1s peak. b) Spectra of the strontium 3d 5/2 and 3/2 peaks. c) Spectra of the cobalt 2p peak. d) Spectra of the oxygen 1s peak.
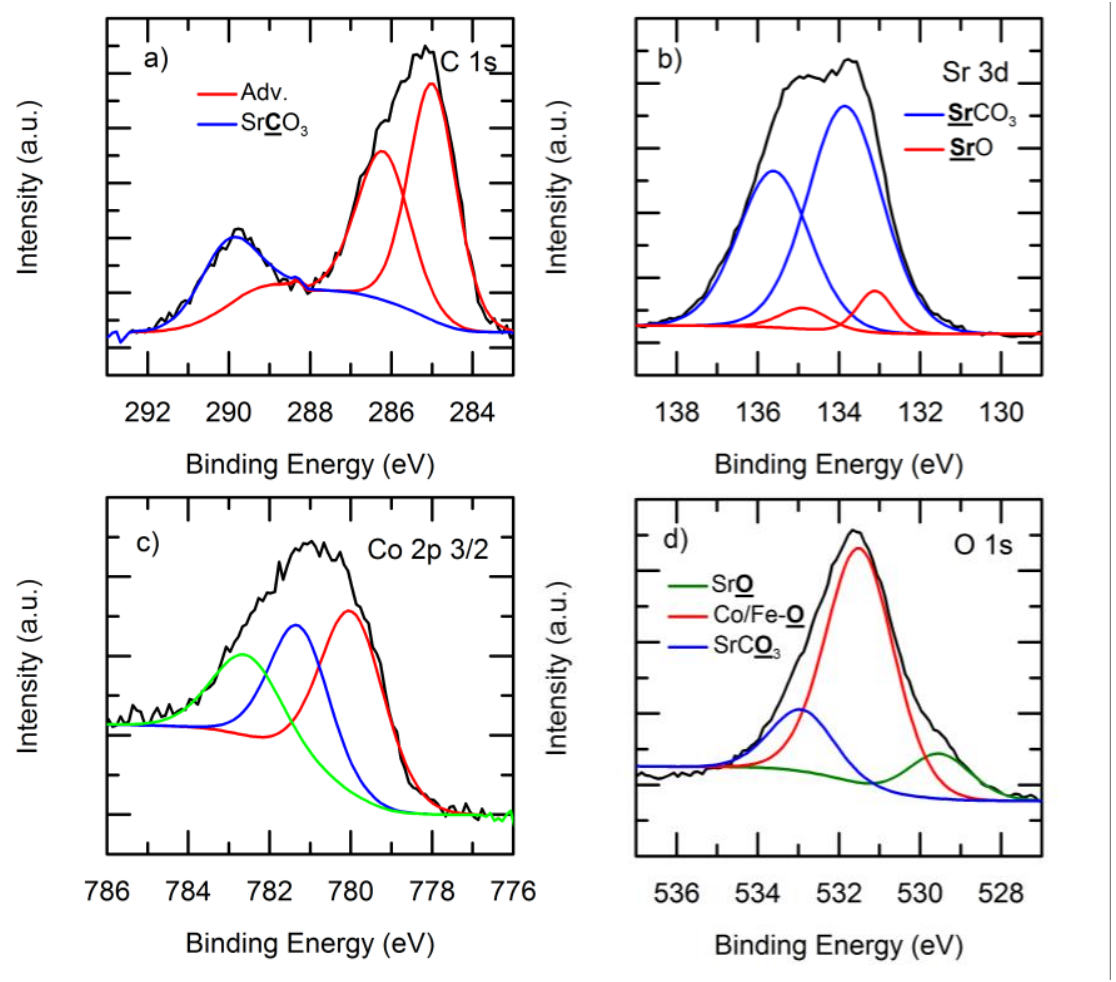

Figure S6. XPS spectra and fitted peaks for the $10 \%$ Sc-SCO sample. a) Spectra of the carbon 1s peak. b) Spectra of the strontium 3d 5/2 and 3/2 peaks. c) Spectra of the cobalt 2p peak. d) Spectra of the oxygen 1s peak. 

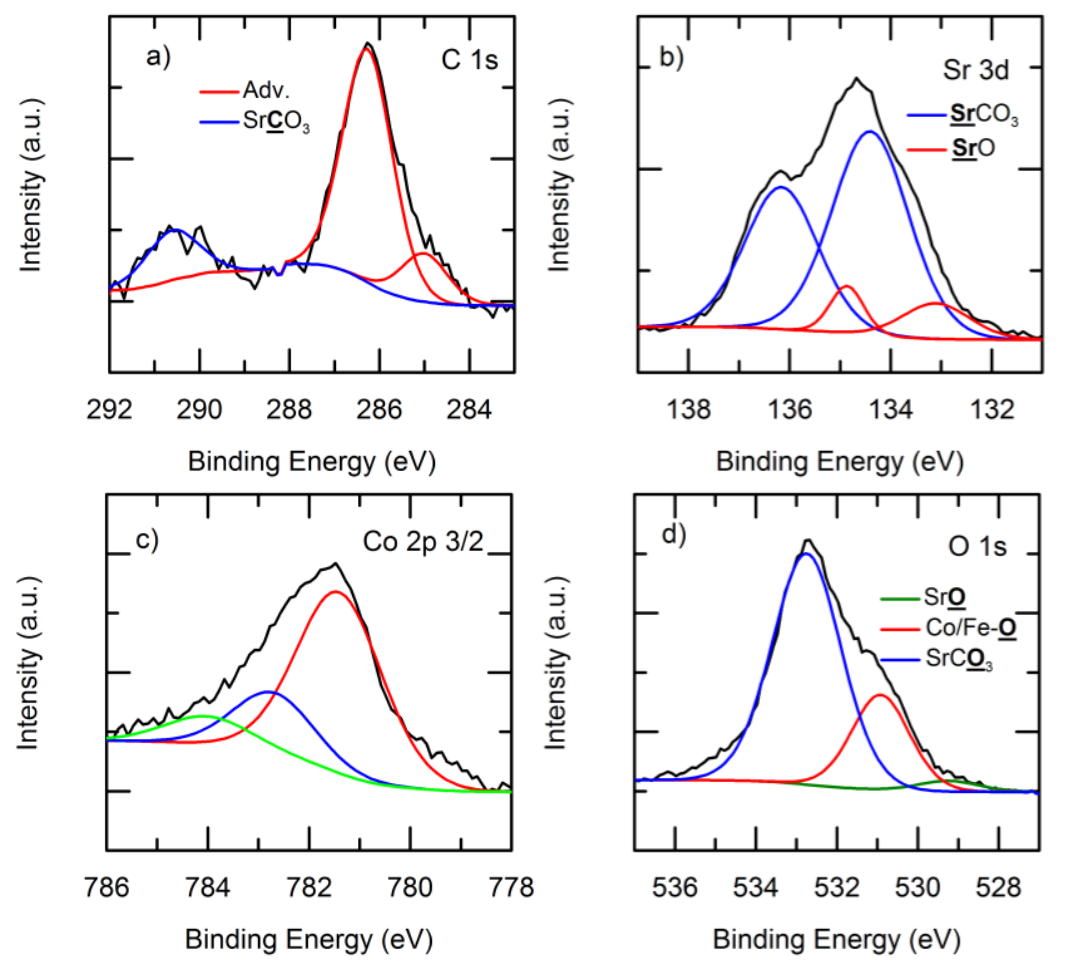

Figure S7. XPS spectra and fitted peaks for the UnSCO sample. a) Spectra of the carbon 1s peak. b) Spectra of the strontium $3 d 5 / 2$ and $3 / 2$ peaks. c) Spectra of the cobalt 2 p peak. d) Spectra of the oxygen 1s peak. 

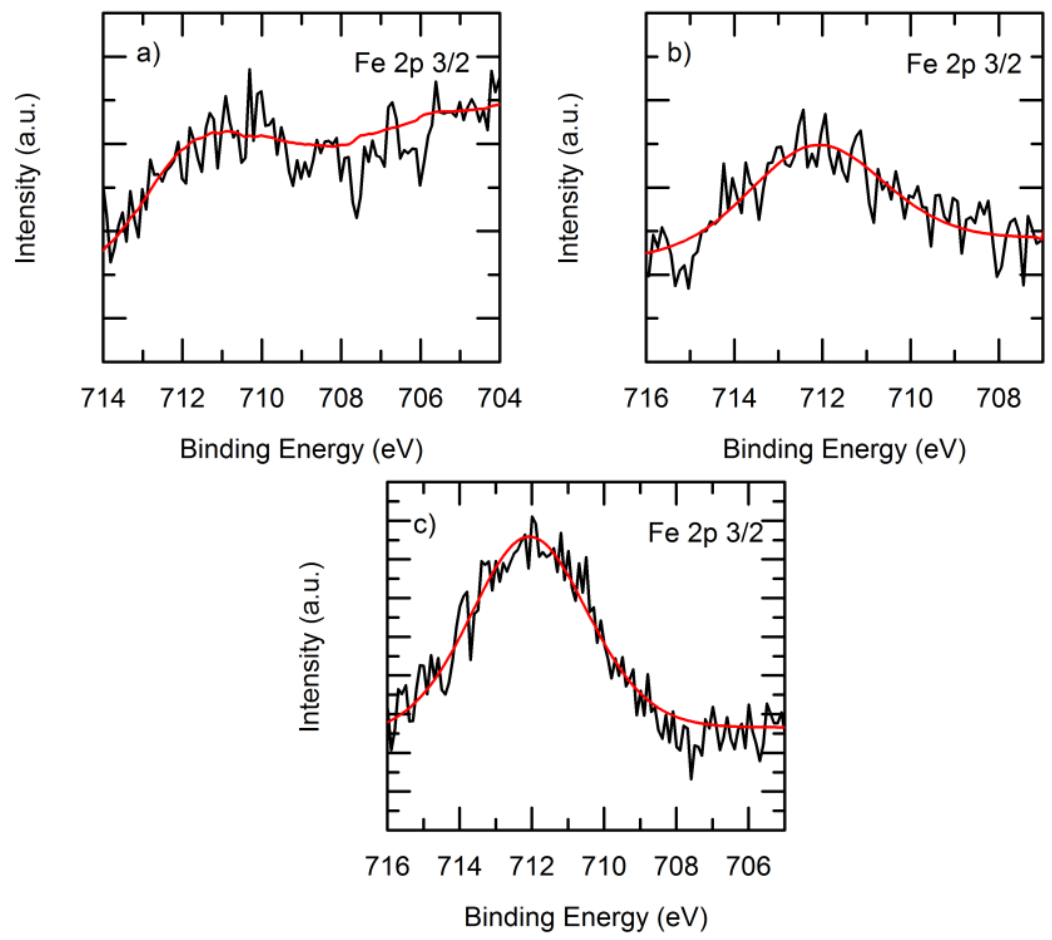

Figure S8. XPS spectra and fitted peaks for the Fe 2p 3/2 peaks of the Fe-SCO samples. a) $1 \% \mathrm{Fe}-\mathrm{SCO}$ b) $5 \% \mathrm{Fe}-$ $\mathrm{SCO}$ c) $10 \% \mathrm{Fe}-\mathrm{SCO}$
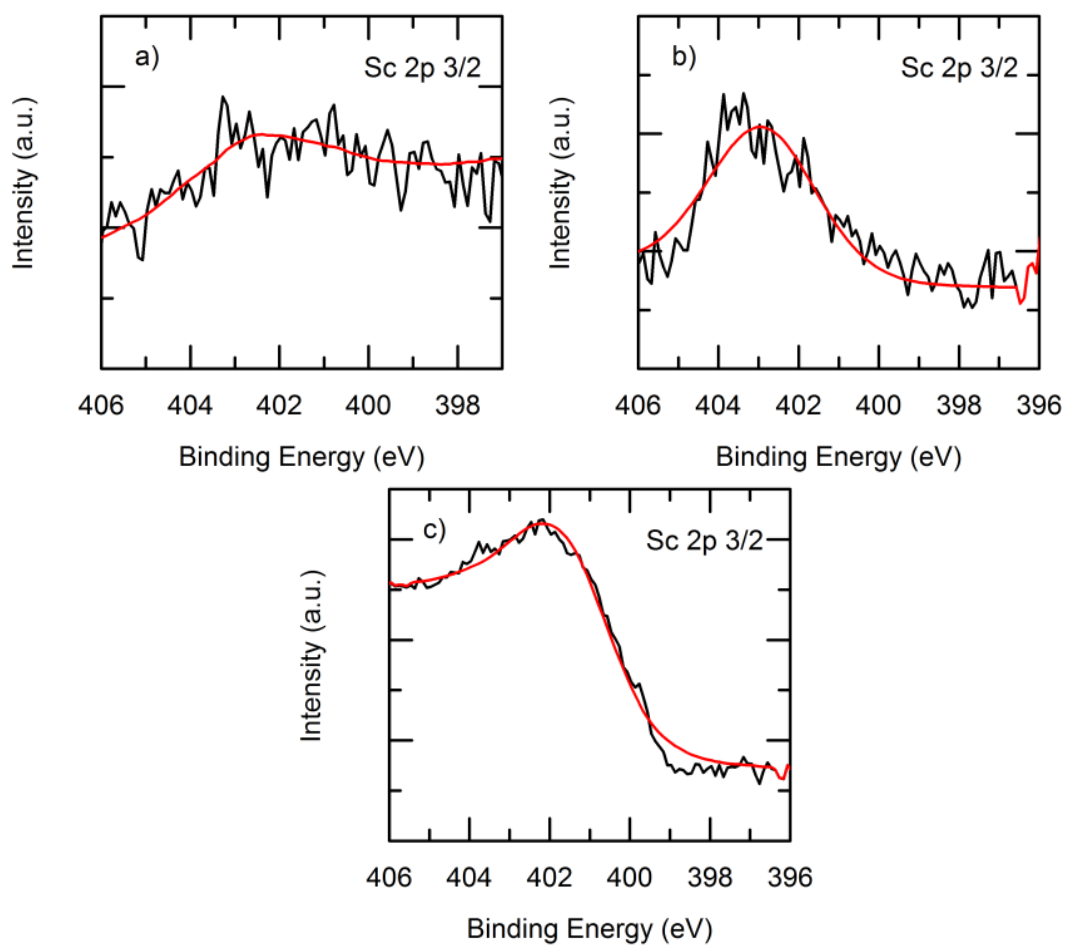

Figure S9. XPS spectra and fitted peaks for the Sc $2 p$ 3/2 peaks of the Sc-SCO samples. a) $1 \% \mathrm{Sc}-\mathrm{SCO}$ b) $5 \% \mathrm{Sc}-$ $\mathrm{SCO}$ c) $10 \% \mathrm{Sc}-\mathrm{SCO}$ 


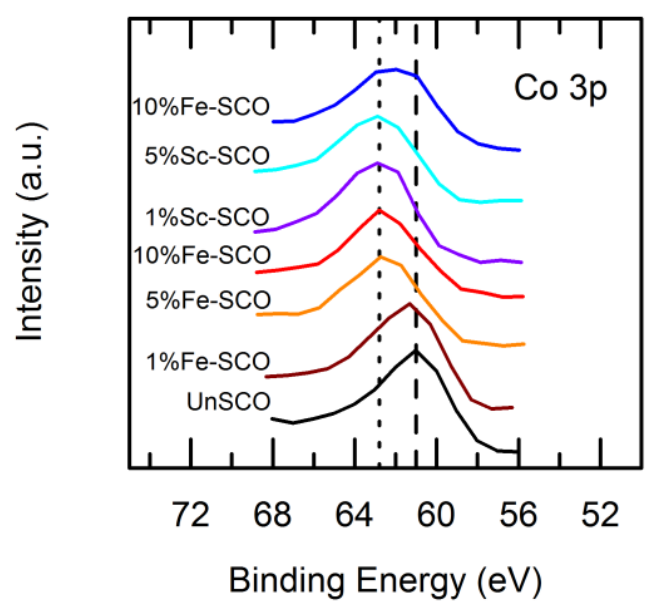

Figure S10. XPS spectra of the Co 3p region in all SCO samples. The dashed line lies on $61.0 \mathrm{eV}$, the dotted line lies on $62.8 \mathrm{eV}$ 


\section{TEM Figures of SCO Powders}
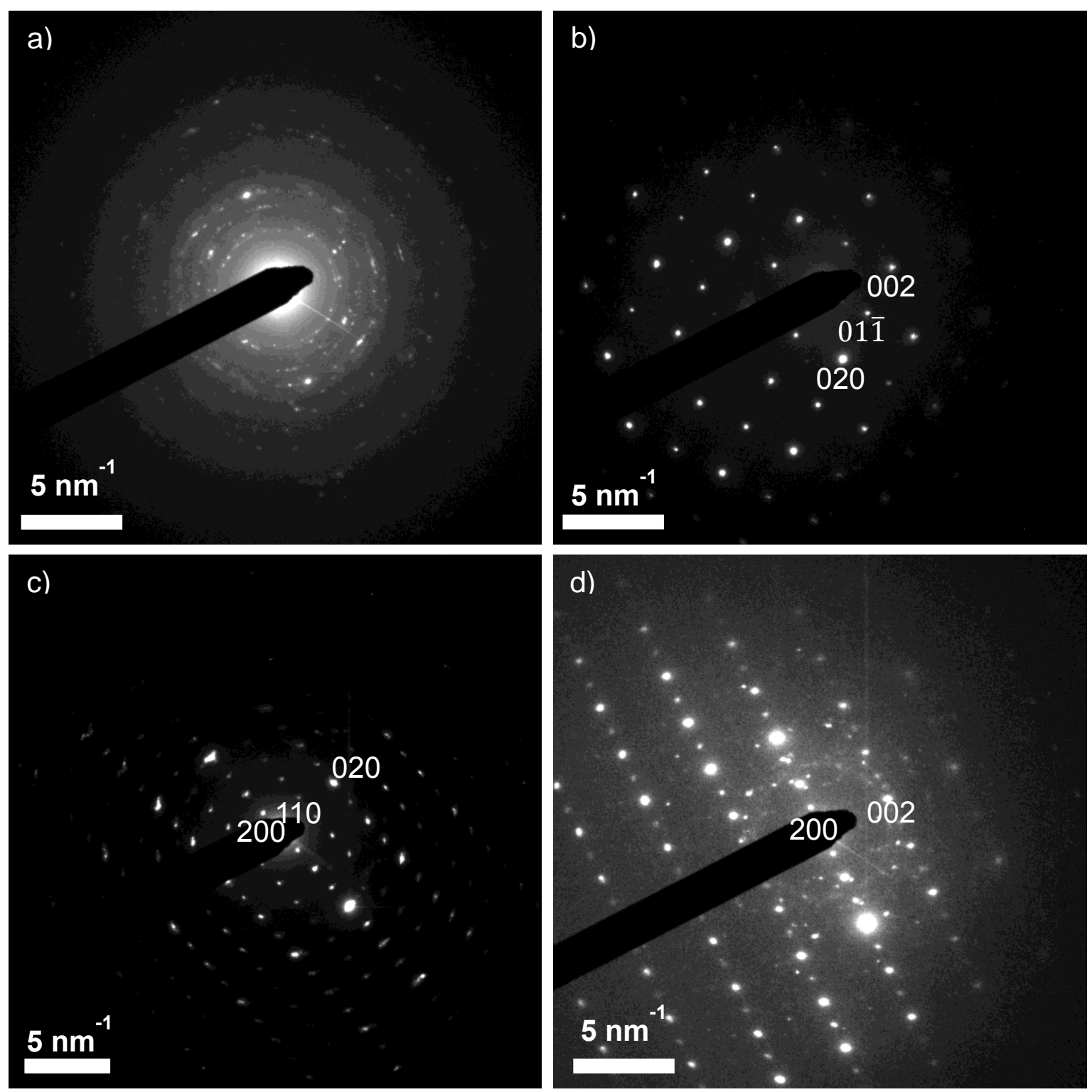

Figure S11. Selected area electron diffraction patterns of a) UnSCO, b) 5\%Fe-SCO, c) 10\%Fe-SCO), and d) $10 \%$ Sc-SCO showing the polycrystalline nature of the undoped material. The other diffraction patterns have been indexed as orthorhombic $\mathrm{SrCoO}_{2.5}$. 


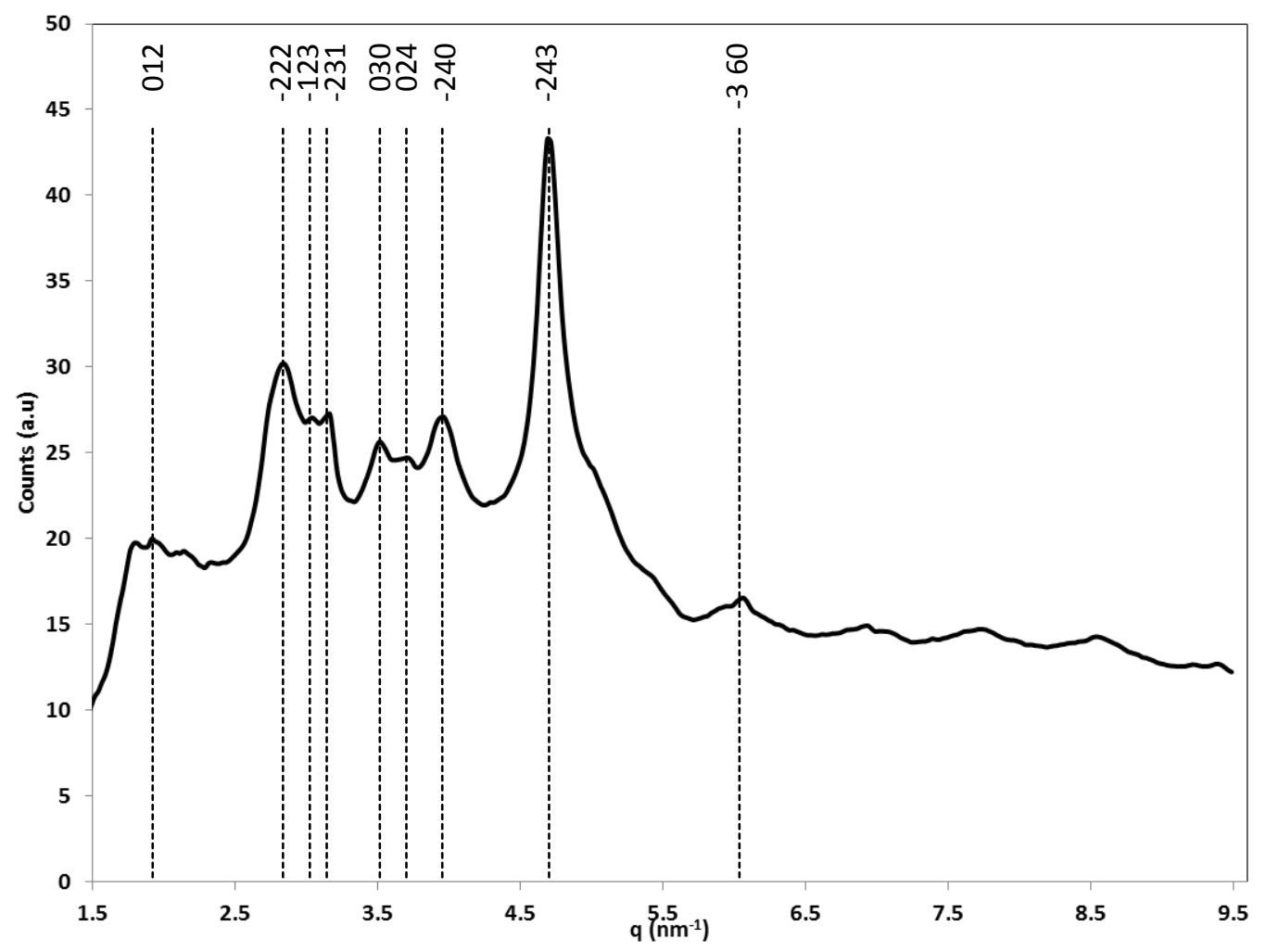

Figure S12. Radial distribution plot of the SAED in Figure SX1 for UnSCO integrated over $360^{\circ}$ indexed as trigonal $\mathrm{Sr}_{6} \mathrm{Co}_{5} \mathrm{O}_{15}$. 

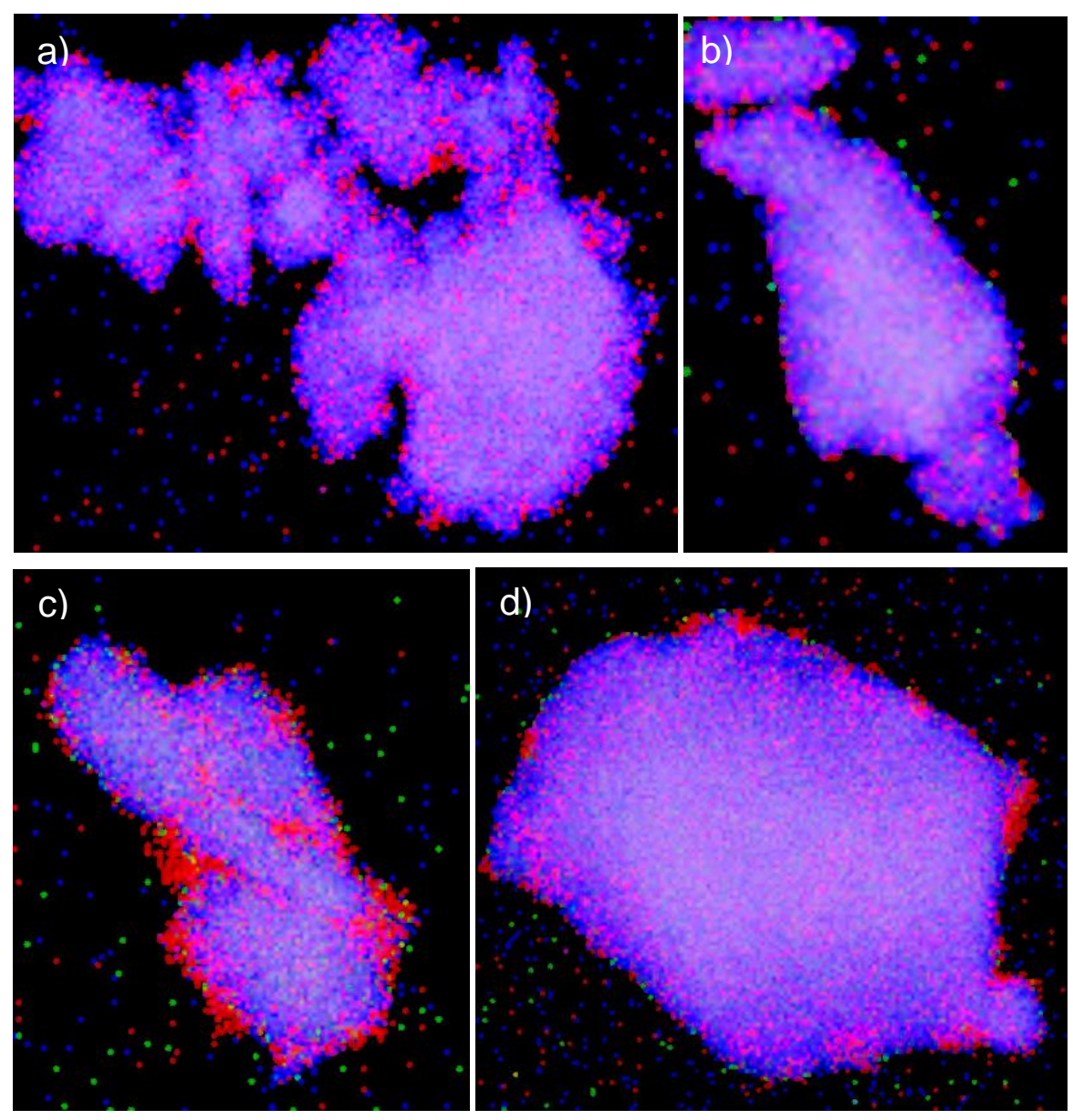

Figure S13. Electron dispersive X-ray spectroscopy maps of a) UnSCO, b) 5\%Fe-SCO, c) $10 \% \mathrm{Fe}-\mathrm{SCO}$, and d) $10 \%$ $\mathrm{Sc}-\mathrm{SCO}$. Cobalt is blue, strontium is red, and the dopant $(\mathrm{Fe}$ or $\mathrm{Sc})$ is green. 


\section{SEM Figures of All SCO Electrodes}

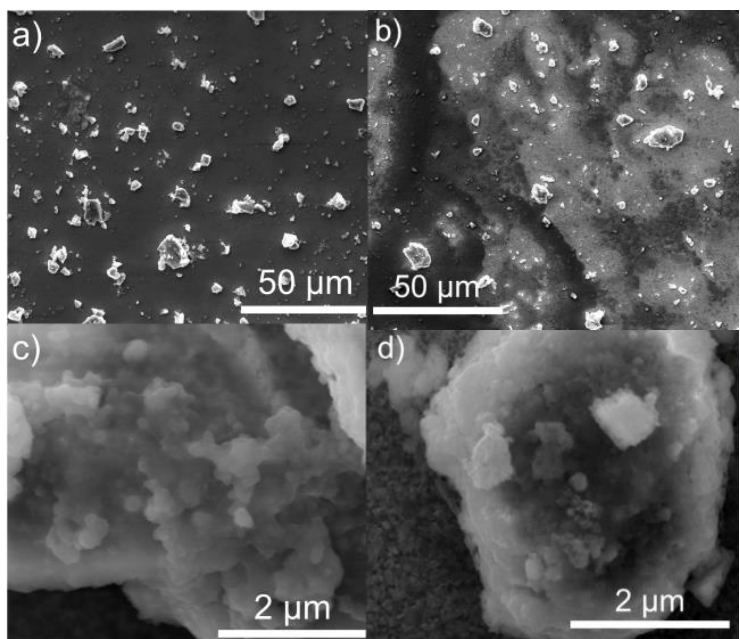

Figure S14. SEM images of a) $10 \% \mathrm{Fe}-\mathrm{SCO}$ and $b$ ) undoped SCO microparticle catalyst on conductive FTO substrate. Surface morphology for the c) $10 \% \mathrm{Fe}-\mathrm{SCO}$ and d) undoped SCO microparticles both appear rough, and composed of sintered microparticles.

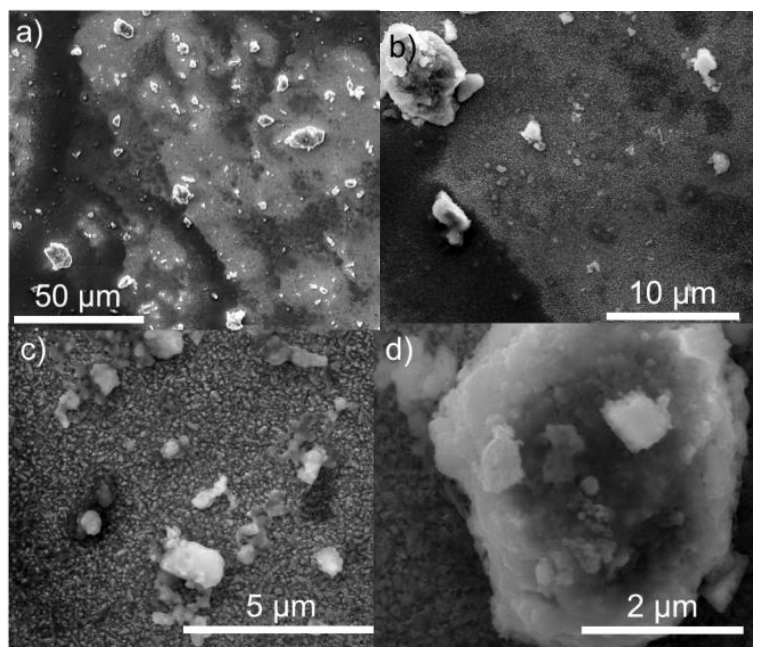

Figure S15. SEM images of UnSCO Electrode

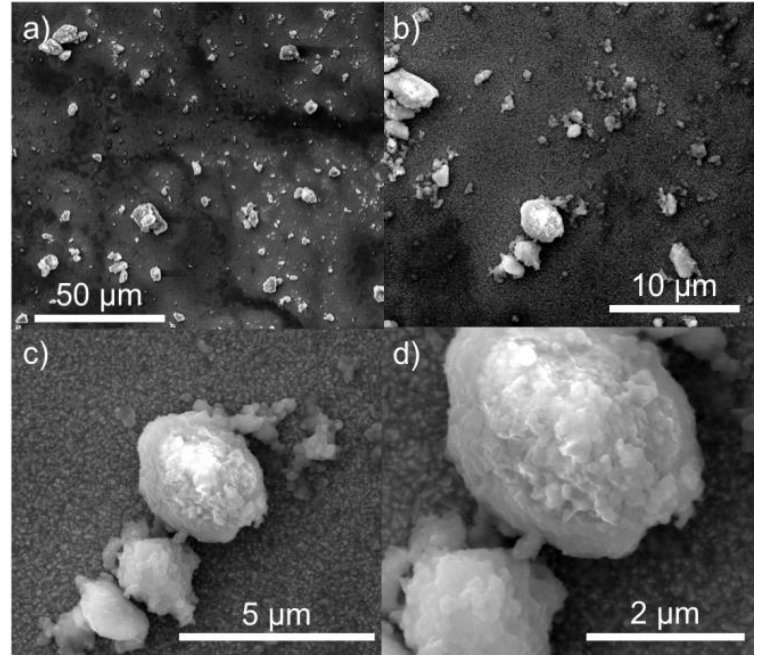

Figure S16. SEM images of $1 \% \mathrm{Fe}-\mathrm{SCO}$ Electrode

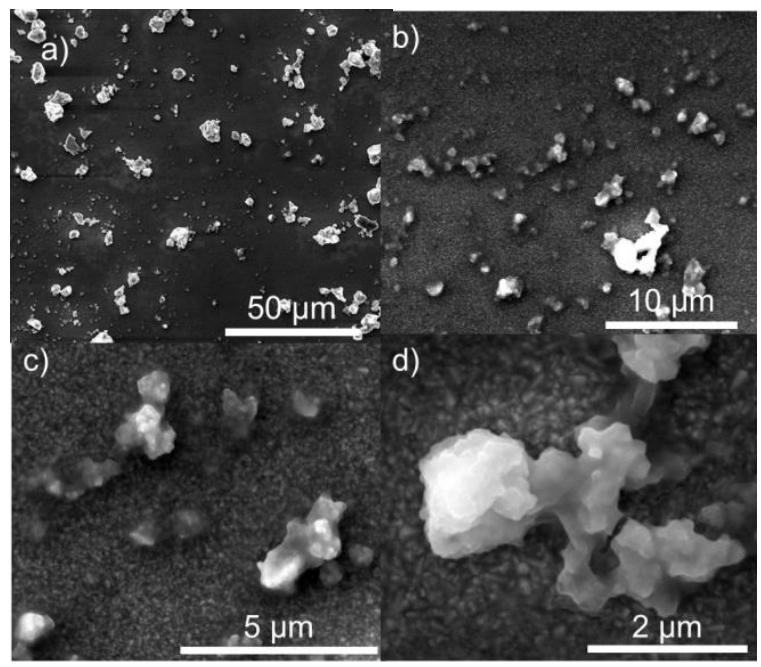

Figure S17. SEM images of 5\%Fe-SCO Electrode 


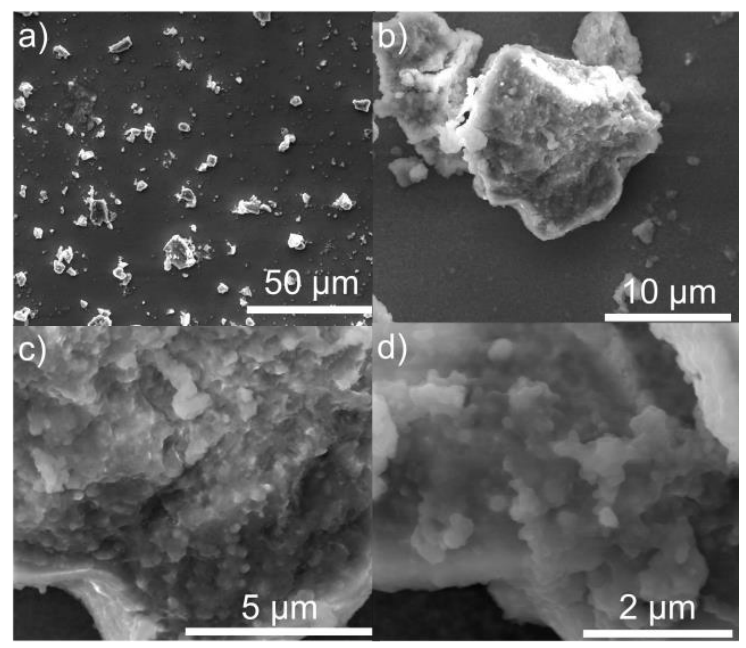

Figure S18. SEM images of $10 \% \mathrm{Fe}-\mathrm{SCO}$ Electrode

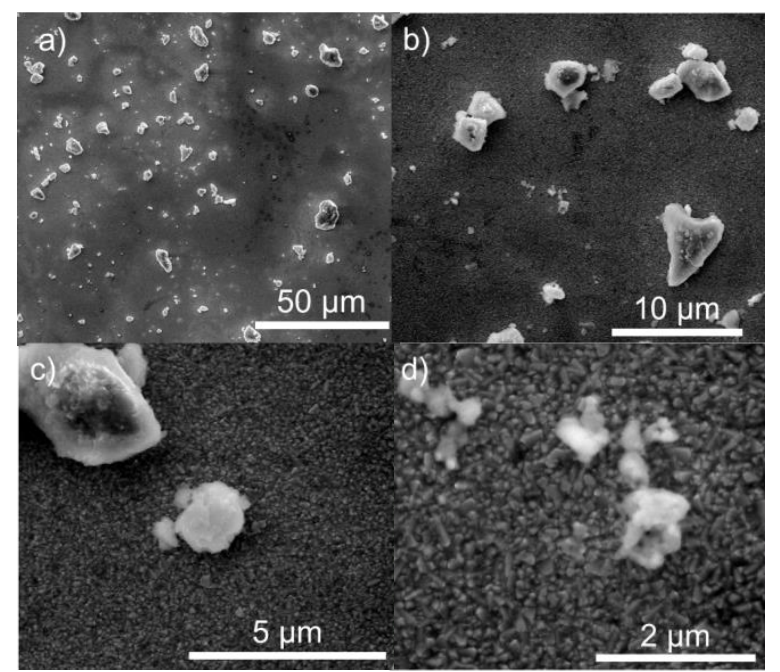

Figure S19. SEM images of $1 \%$ Sc-SCO Electrode

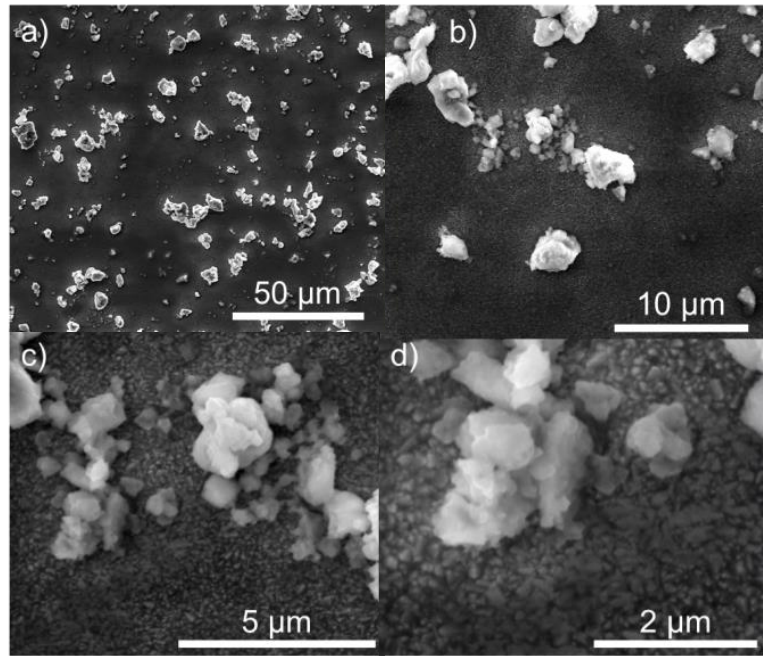

Figure S20. SEM images of 5\%Sc-SCO Electrode

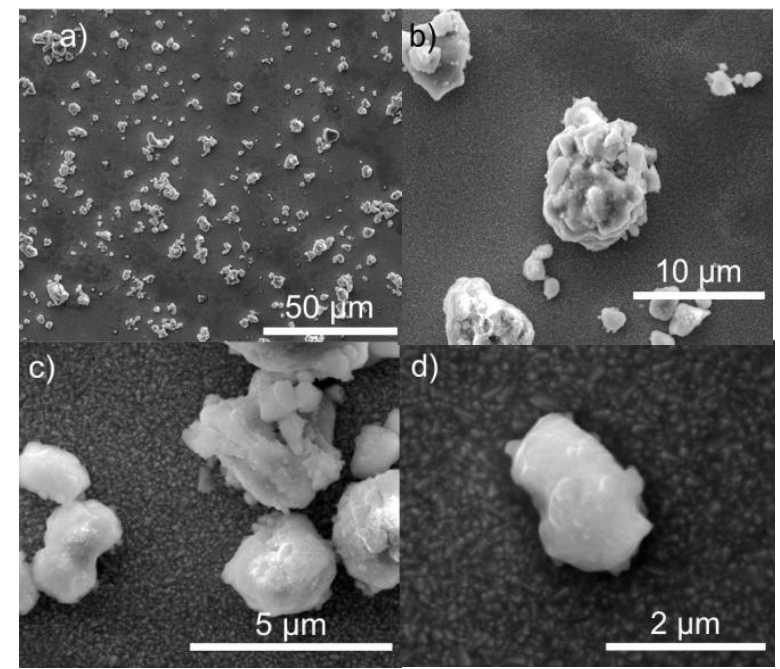

Figure S21. SEM images of 10\%Sc-SCO Electrode 


\section{OER Performance}

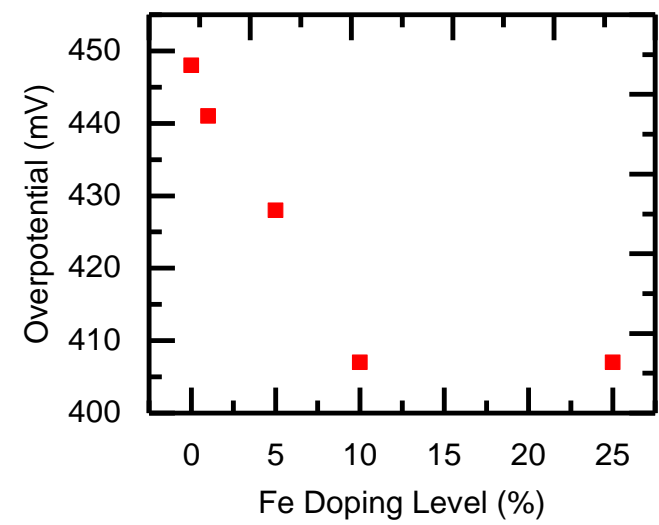

Figure S22. Plot of measured overpotential at 10 $\mathrm{mA} / \mathrm{cm}^{2}$ versus $[\mathrm{Fe}]$ in several $\mathrm{Fe}$-doped $\mathrm{SCO}$ electrodes

\section{Supporting Tables}

Table S1: Tolerance values for the seven selected SCO samples examined in this study. $t$ shows a transition to unity with increasing concentrations of both $\mathrm{Fe}$ and $\mathrm{Sc}$ dopants.

\begin{tabular}{|c|c|}
\hline Sample & $t$ \\
\hline UnSCO & 1.002 \\
\hline $1 \%$ Fe-SCO & 1.002 \\
\hline $5 \%$ Fe-SCO & 1.001 \\
\hline $10 \%$ Fe-SCO & 1.000 \\
\hline $1 \%$ Sc-SCO & 1.001 \\
\hline $5 \%$ Sc-SCO & 0.996 \\
\hline $10 \%$ Sc-SCO & 0.989 \\
\hline
\end{tabular}

Table S2: Atomic percentage of Fe and Sc dopants as measured using XPS, and the binding energy of the 2 p $3 / 2$ peaks both elements.

\begin{tabular}{|c|c|c|}
\hline Sample & $\begin{array}{c}\text { Percent Fe/Sc } \\
(\%)\end{array}$ & $\begin{array}{c}\text { Binding } \\
\text { Energy } \\
(\mathrm{eV})\end{array}$ \\
\hline $1 \% \mathrm{Fe}-\mathrm{SCO}$ & 1.14 & 711.9 \\
\hline $5 \% \mathrm{Fe}-\mathrm{SCO}$ & 3.78 & 712.2 \\
\hline $10 \% \mathrm{Fe}-\mathrm{SCO}$ & 9.10 & 712.9 \\
\hline $1 \% \mathrm{Sc}-\mathrm{SCO}$ & 3.95 & 402.7 \\
\hline $5 \% \mathrm{Sc}-\mathrm{SCO}$ & 5.18 & 402.9 \\
\hline $10 \% \mathrm{Sc}-\mathrm{SCO}$ & 13.61 & 401.6 \\
\hline
\end{tabular}

Table S3: FWHM and Co 2p 3/2 binding energies for the Fe-SCO samples. As iron concentration increases, the FWHM of the peak increases as well.

\begin{tabular}{|c|c|c|}
\hline Sample & $\begin{array}{c}\text { Binding } \\
\text { Energy (eV) }\end{array}$ & FWHM \\
\hline $1 \% \mathrm{Fe}-\mathrm{SCO}$ & 780.2 & 2.49 \\
\hline $5 \% \mathrm{Fe}-\mathrm{SCO}$ & 781.5 & 3.20 \\
\hline $10 \% \mathrm{Fe}-\mathrm{SCO}$ & 781.2 & 3.37 \\
\hline
\end{tabular}


Table S4: OER mass activities of several perovskites. $\mathrm{LaNiO}_{3}, \mathrm{LaNi}_{0.75} \mathrm{Fe}_{0.25} \mathrm{O}_{3}, \mathrm{LaCoO}_{3}$, and $\mathrm{LaMnO}_{3}$ are all supported on $\mathrm{N}$-doped carbon on a glassy carbon rotating disk electrode.

\begin{tabular}{|c|c|}
\hline Sample & $\begin{array}{c}\text { Mass } \\
\text { Activity } \\
\text { (mA/mg) }\end{array}$ \\
\hline $\mathrm{SrCo}_{0.9} \mathrm{Fe}_{0.1} \mathrm{O}_{3-\delta}$ & 6.5 \\
\hline $\mathrm{LaNiO}_{3}{ }^{*}$ & 90.0 \\
\hline $\mathrm{LaNi}_{0.75} \mathrm{Fe}_{0.25} \mathrm{O}_{3}{ }^{*}$ & 82.0 \\
\hline $\mathrm{LaCoO}_{3}{ }^{*}$ & 100.0 \\
\hline $\mathrm{LaMnO}_{3}{ }^{*}$ & 92 \\
\hline
\end{tabular}

*Adapted from Reference 51 